\title{
ANALISIS HUBUNGAN ANTARA PENYAKIT HIPERTENSI DENGAN KADAR KOLESTEROL TOTAL PADA MASYARAKAT DI WILAYAH KERJA PUSKESMAS MAMAJANG KOTA MAKASSAR
}

Analysis of the relationship between hypertension disease with total cholesterol levels in communities in the working area of mamajang puskesmas, makassar city

\author{
Rahman $^{1}$, Nurdin $^{2}$, Muhammad Nuralamsyah ${ }^{3}$ \\ ${ }_{1,2}$ Jurusan Analis Kesehatan Poltekkes Makassar \\ ${ }^{3}$ Prodi Keperawatan Parepare Poltekkes Makasar
}

Koresponden : rahmancarallang@gmail.com

\begin{abstract}
Research on the analysis of the relationship between hypertension and total cholesterol levels in the community in the working area of Puskesmas Mamajang, Makassar city has been conducted. High levels of cholesterol in the blood are a serious problem because they are a risk factor for various non-communicable diseases such as heart disease, stroke, and diabetes mellitus. Based on studies that have been carried out, the risk of atheroclerosis which is the cause of CHD will increase if the total cholesterol level in the blood exceeds the normal limit. As for the purpose of this study is to describe the analysis of the relationship between total cholesterol levels and blood pressure in hypertensive sufferers. The method used in this research is cross sectional method. Determination of cholesterol levels used the Point Of Care Test (POCT) method using the Auto Cholesterol Check Tool. The sample used in this study were 50 people who were in the working area of the Mamajang Health Center in Makassar City with complaints of high blood pressure (hypertension). Based on the results of the study, it was found that out of 50 respondents, $31(62 \%)$ respondents experienced cholesterol levels exceeding normal levels $\geq 200$ mg.dl), Based on statistical results with the Pearson Chi Squer test, a significance value of 0.764> ('́ 0.05) was obtained. so it is concluded that there is no significant relationship. From these results, it is suggested that every citizen with hypertension should carry out regular health checks, especially cholesterol levels. Keywords : Hypertension, Total Cholesterol, Puskesmas Mamajang
\end{abstract}

\begin{abstract}
ABSTRAK
Telah dilakukan penelitian tentang Analisis hubungan antara penyakit hipertensi dengan kadar kolesterol total pada masyarakat di wilayah kerja Puskesmas Mamajang kota Makassar. Tingginya kadar kolesterol di dalam darah merupakan permasalahan yang serius karena merupakan salah satu faktor risiko dari berbagai macam penyakit tidak menular seperti jantung, stroke, dan diabetes mellitus. Berdasarkan penelitian-penelitian yang telah dilakukan risiko terjadinya ateroklerosis yang merupakan penyebab PJK akan meningkat apabila kadar kolesterol total di dalam darah melebihi batas normal. Adapun yang menjadi tujuan dari penilitian ini adalah untuk mengetahui gambaran analisis hubungan kadar kolesterol total dengan tekanan darah penderita hipertensi. Metode yang digunakan dalam penilitian ini adalah metode Cross sectional. Penentuan kadar kolesterol digunakan metode Point Of Care Test (POCT) dengan menggunakan alat Auto
\end{abstract}


Check Kolesterol. Sampel yang digunakan dalam penilitian ini adalah warga yang berada di wilayah kerja Puskesmas Mamajang Kota Makassar sebanyak 50 orang dengan keluhan tekanan darah tinggi (Hipertensi). Berdasarkan hasil penilitian didapatkan bahwa dari 50 responden terdapat $31(62 \%)$ responden mengalami kadar kolesterol melebihi dari kadar normal ( $\geq 200 \mathrm{mg}$.dl), Berdasarkan hasil statistik dengan uji Pearson Chi Squer didapatkan nilai signifikasnsi sebesar 0,764 > (á 0,05) sehingga disimpulkan bahwa tidak terdapat hubungan yang bermakna. Dari hasil tersebut disaran agar setiap warga yang mengalami hipertensi untuk senantiasa melakukan pemeriksaan kesehatan secara berkala terutam pemeriksaan kadar kolesterol.

Kata kunci : Hipertensi, Kolesterol Total, Puskesmas Mamajang

\section{PENDAHULUAN}

Penyakit Tidak Menular (PTM) merupakan salah satu masalah kesehatan yang telah menjadi perhatian nasional maupun global. Saat ini PTM merupakan penyebab kematian terbanyak di Indonesia. Keadaan dimana penyakit tidak menular masih merupakan masalah kesehatan penting dan dalam waktu bersamaan morbiditas dan mortalitas makin meningkat yang meru pakan beban ganda dalam pelayanan kesehatan. Sehinnga menyebabkan pergeseran pola penyakit saat ini. Riskesdas 2018 menunjukkan prevalensi Penyakit Tidak Menular mengalami kenaikan jika dibandingkan dengan Riskesdas 2013, antara lain kanker, stroke, penyakit ginjal kronis, diabetes melitus, dan hipertensi. Prevalensi kanker naik dari 1,4\% (Riskesdas 2013) menjadi 1,8\%, prevalensi stroke naik dari $7 \%$ menjadi $10,9 \%$; dan penyakit ginjal kronik naik dari $2 \%$ menjadi $3,8 \%$. Berdasarkan pemeriksaan gula darah, diabetes melitus naik dari $6,9 \%$ menjadi $8,5 \%$; dan hasil pengukuran tekanan darah, hipertensi naik dari 25,8\% menjadi 34,1\%(Kemenkes, 2018).

Kenaikan prevalensi penyakit tidak menular ini berhubungan dengan pola hidup saat ini. Seiring dengan perkembangan zaman yang makin modern, membuat sebagian orang mengalami pola hidup yang tidak sehat. Pola makan yang tidak sehat, seperti seringnya mendatangi restoran cepat saji yang menyajikan makanan tinggi kalori dan kolesterol, ditambah kurang berolahraga, aktivitas merokok, dan minum minuman beralkohol, merupakan pangkal dari munculnya hiperkolesterolemia. Kesibukan yang luar biasa dan jadwal kerja yang sangat padat membuat kita sering melupakan makan. Kita makan seadanya, dengan menu yang seringkali itu-itu juga. Karena diburu waktu dan ingin cepat, kita memilih makan makanan cepat saji. Tidak peduli itu dianggap makanan sampah. Pola makan yang tidak sehat cenderung merugikan tubuh. Waktu makan yang tidak teratur dapat menyebabkan maag dan nyeri lambung. Terlalu sering makan makanan dari resto cepat saji dapat mengakibatkan kolesterol tinggi dan bahkan kanker. Makan makanan instan yang mengandung pengawet, MSG dan zatzat kimia lainnya dapat mengakibatkan munculnya berbagai macam penyakit. (Soenarwo, 2013).

Selain dari pola makan, kesibukan yang sangat padat dan tuntutan pekerjaan yang tinggi ini juga berdampak pada aktivitas fisik seseorang. kita menjadi tidak memiliki waktu yang cukup untuk berolahraga dan merasa sangat lelah untuk dapat meluangkan waktu kita untuk berolahraga. Selain itu di zaman yang makin maju dan berkembang ini 
membuat orang semakin mudah dalam memenuhi kebutuhannya tanpa perlu melakukan banyak pergerakan. Seperti halnya makin mudahnya mengakses situs-situs toko online yang mempermudah seseorang dalam memenuhi kebutuhannya hanya dengan memainkan handphone ditangan tanpa perlu berjalan keluar rumah untuk berbelanja. Hal ini tentu berdampak negatif pada berkurangnya aktivitas fisik yang dapat dilakukan seseorang. kurang bergerak/ berolahraga bisa meningkatkat LDL (kolesterol jahat) dan menurunkan HDL (kolesterol baik) dalam tubuh.

Pola hidup yang lainnya yang tanpa sadar sering kita abaikan namun sesungguhnya memberikan dampak yang besar bagi kesehatan kita adalah waktu tidur. Banyaknya waktu yang tersita untuk mengurusi berbagai aktivitas atau pekerjaan, sehingga menjadikan seseorang begitu menikmati kesibukannya dan mengabaikan waktu tidur bagi tubuh kita. Tuntutan pekerjaan yang terkadang membuat seseorang harus menghadapi lembur, serta berbagai kesibukan lainnya tanpa disadari sangat menguras waktu kita dan membuat kita mengabaikan waktu istirahat yang cukup bagi tubuh itu sendiri. Kurangnya waktu dan kualitas istirahat dapat menyebabkan berbagai masalah bagi kesehatan termasuk metabolisme yang tedapat dalam tubuh kita. (Beavers,.D.G, 2008)

Tingginya kadar kolesterol di dalam darah merupakan permasalahan yang serius karena merupakan salah satu faktor risiko dari berbagai macam penyakit tidak menular seperti jantung, stroke, dan diabetes mellitus. Berdasarkan penelitian-penelitian yang telah dilakukan risiko terjadinya ateroklerosis yang merupakan penyebab PJK akan meningkat apabila kadar kolesterol total di dalam darah melebihi batas normal. Kadar kolesterol yang berlebih dalam darah akan mudah melekat pada dinding sebelah dalam pembuluh darah. Proses ini biasanya disebut dengan atherosklerosis. Agar kadar kolesterol total bisa turun, bisa dilakukan dengan menjalankan metode sederhana, seperti mengubah pola makan dengan mengurangi makanan tinggi lemak jenuh, menurunkan berat badan, olahraga, istirahat yang cukup, dan menghentikan kebiasaan merokok (Fikri, 2009).

\section{METODE}

Jenis Penelitian yang digunakan adalah analisis bersifat Cross sectional untuk mengetahui gambaran hubungan kadar kolesterol dengan tekanan darah pada penderita hipertensi di wilayah Puskesmas Mamajang Kota Makassar. Penelitian ini telah dilaksanakan mulai tanggal 14 Juli 2020 sampai 10 September 2020 di Puskesmas Mamajang Kota Makassar Populasi dari penelitian ini adalah semua masyarakat di wilayah kerja Puskesmas Mamajang Kota Makassar. Sampel dalam penelitian ini adalah masyarakat di wilayah Kerja Puskesmas Mamajang Kota Makassar yang mengalami penyakit hipertensi.sebanyak 50 responden yang diambil secara accidental sampling.

\section{Bahan dan Instrumen Penelitian}

Bahan penelitian ini adalah darah (wool blood) pasien, reagen siap pakai untuk pemeriksaan Kolesterol, Alkohol 70\%. Instrumen penelitian ini terdiri dari Auto Check Kolesterol, Auto Click, Lanset, torniquet, Tensi meter, tabung vakum, sentrifus, mikropipet, tip. 


\section{Prosedur Kerja Penelitian}

\section{Pra Analitik}

Persiapan Pasien yakni puasa 10 - 14 jam termasuk menghentikan rokok dan olahraga tetapi diperbolehkan minum air putih. Tidak mendapat obat yang mempengaruhi kadar kolesterol dalam 2 minggu terakhir. Pasien dalam keadaan stabil, tidak ada perubahan berat badan, pola makan, kebiasaan merokok, minum kopi dan alkohol dalam 2 minggu terakhir sebelum tes.Pasien tidak sedang mengalami stres oleh penyakit akut.

Persiapan Sampel yakni sebelum pengambilan sampel darah, pasien dalam posisi duduk. Responden mengisi kuisioner yang telah diberikan dengan mengisi dengan benar.

\section{Analitik}

Pertama tekan on/off, periksa Washer, Rinse, rak kuvet, reagen dan dilakukan kontrol sebelum alat digunakan, setelah semua selesai alat siap dioperasikan. Setelah itu strip kolesterol dimasukkan ke dalam alat auto kolesterol. Kemudian ambil darah menggunakan pipet volumetrik $20 \mu \mathrm{l}$. Lalu sentuhkan ujung pipet pada strip kolesterol. Biarkan alatnya kulang lebih 20 detik dan nilainya akan tertera pada alat baca. Kemudian catat hasil yang tertera pada alat tersebut.

\section{Analisa Data}

Analisa data dalam penelitian ini yaitu dianalisis secara sederhana dengan menghitung presentase responden yang mengalami kadar kolesterol yang melebihi dari kadar normal $(<200 \mathrm{mg} / \mathrm{dl})$ dan disajikan dalam bentuk tabel yang dinarasikan.

\section{HASIL}

Berdasarkan hasil pengisian kuesioner pada pendistribusian responden berdasarkan jenis kelamin didapatkan hasil yaitu menunjukkan bahwa dari 55 responden terdapat 11 (22\%) orang laki-laki dan 39 (78\%) orang perempuan. Sedangkan hasil distribusi responden berdasarkan kadar kolesterol menunjukkan bahwa terdapat $19(380 \%)$ responden yang mengalami kadar kolesterol yang norma $(<200$ $\mathrm{mg} / \mathrm{dl})$, dan $31(62 \%)$ responden yang mengalami kadar kolesterol yang melebihi dari normal ( $\geq 200 \mathrm{mg} / \mathrm{dl}$ ). Selanjutnya hasil distribusi responden berdasarkan tekanan darah kategori hipertensi menunjukkan bahwa dari 50 responden terdapa 31 (62\%) orang dengan tekanan darah normal, dan 19 (38\%) orang mengalami tekanan darah tinggi. Kemudian distribusi responden dengan kadar kolesterol berdasarkan jenis kelamin, menunjukkan bahwa dari 31 responden, maka terdapat $5(16,1 \%)$ jenis kelamin laki-laki, dan $26(83,9 \%)$ perempuan.

\section{PEMBAHASAN}

Kadar kolesterol dalam darah umumnya berasal dari menu makanan yang dikonsumsi. Semakin banyak makan makanan berlemak, semakin berpeluang menaikkan kadar kolesterol. Makanan seperti gorengan, minyak kelapa/ kelapa sawit, alpukat, durian, daging berlemak, jeroan, kacang tanah, dan sejenisnya. Kolesterol terdapat di jaringan dan plasma sebagai kolesterol bebas atau dalam bentuk simpanan, yang berikatan dengan asam lemak rantai-panjang sebagai ester kolesteril. Di dalam plasma, kedua bentuk tersebut diangkut dalam lipoprotein. (McPhee, Stephen J., William F. Ganong. 2015)

Penyakit hipertensi setiap tahun meningkat dan diperkirakan di tahun 2025 jumlahnya bertambah menjadi 1,56 milyar orang atau $60 \%$ dari jumlah penduduk dewasa dunia (Ridwan, 
2002). Khusus di Indonesia, diprediksi penderita hipertensi terdapat 15 juta orang, tetapi hanya $4 \%$ yang merupakan hipertensi terkontrol. Hipertensi dijuluki "Silent Killer" atau si pembunuh diam-diam karena merupakan penyakit tanpa tanda dan gejala yang khas. Anggapan Masyarakat terhadap hipertensi hal yang biasa sehingga hanya nampak jika sudah parah dan menimbulkan komplikasi yang sangat berbahaya seperti stroke (Robert E., Kowalski, 2010).

Hipertensi disebabkan oleh beberapa faktor antara lain genetik, aktivitas fisik (olahraga) dan tingkat stress, konsumsi makanan yang tidak sehat, perilaku yang tidak sehat seperti merokok. Menurut Data Riset Kesehatan Dasar tahun 2018 menyebutkan prevalensi hipertensi pada usia 25-34 tahun sebesar 2,07\% sedangkan untuk usia 35-44 tahun sebesar 5,73\%. Berdasarkan tingkat pekerjaan kejadian hipertensi pada PNS sebesar 10,22\% lebih tinggi dibandingkan pegawai swasta sebesar $4,03 \%$. Jenis pekerjaan mempengaruhi tingkat stress seseorang, dimana kejadian stress meningkatkan kejadian hipertensi. Hipertensi menjadi faktor resiko beberapa penyakit antara lain jantung, gagal ginjal, diabetes, stroke dll. Beberapa keadaan yang menyertai hipertensi meningkatkan faktor resiko hipertensi menjadi penyakit lain meskipun etiologi hipertensi belum diketahui secara pasti (Junaidi I, 2010)

Berdasarkan hasil penilitian terhadap kadar kolesterol pada warga masyarakat yang ada di wilayah kerja

\section{KESIMPULAN}

Puskesmas Mamajang kota Makassar yang mengalami penyakit hipertensi didapatkan hasil bahwa dari 50 responden terdapat 31 (62\%) orang dengan kadar kolesterol yang melebihi dari kadar normal ( $\geq 200 \mathrm{mg} / \mathrm{dl}$ ), sedangkan orang dengan kadar kolesterol normal (< $200 \mathrm{mg} / \mathrm{dl})$ terdapat 19 (38\%) orang, dan berdasarkan jenis kelamin maka didapatkan laki-laki yang mengalami hipertensi dan kadar kolesterol yang lebih dari normal sebanyak $5(16,1 \%)$ dari 31 responden, sedangkan untuk perempuan sebanyak $26(83,9 \%)$. Pada penilitian ini sebagian dari responden tidak lagi mengalami tekanan darah yang tinggi pada saat penilitian hal ini disebabkan karena mereka telah mengkonsumsi obat penurun tekanan darah.

Berdasarkan data Penilitian ini sejalan dengan penilitian yang dilakukan oleh Maryati. H, (2017) tentang hubungan adar kolesterol pada penderita hipertensi warga Dusun Sidomulyo Desa Rejoagung Kecamatan Ploso Kabupaten Jombang, dimana hasil penilitiannya mengatakan bahwa dari 34 responden didapatkan hasil 18 $(52,9 \%)$ responden mengalami kadar kolesrterol lebih dari normal. Peniltian oleh Hidayati S dkk (2020) juga mengatakan bahwa terdapat hubungan antara kadar kolesterol dengan keadaan hipertensi pada karyawan Fakultas Psikologi dan Kesehatan UIN Sunan Ampel Surabaya, dimana dari 36 responden didapatkan hasil $19(52,8 \%)$ mengalami hiperkolesterolemia.

Berdasarkan hasil dan pembahasan pada penilitian ini maka dapat ditarik kesimpulan bahwa dari 50 responden penderita hipertensi pada 
masyarakat di wilayah kerja Puskesmas Mamajang kota Makassar terdapat 31 $(62 \%)$ orang mengalami kadar kolesterol yang melebihi kadar normal, namun berdasarkan hasil ujiu statistik metode Pearson Chi Square didapatkan niala signifikansi sebesar $0,764>$ ( 0,05) sehingga dinyatakan tidak hubungan antara kadar kolesterol dengan keadaan hipertensi.

\section{SARAN}

Berdasarkan hasil dan pembahasan dari penilitian ini maka dapat disarankan sebagai berikut : Kepada warga masyarakat diharapkan agar senantiasa melakukan pemeriksaan kesehatan secara berkala.

1. Kapada warga masyarakat yang mengalami tekanan darah tinggi (Hipertensi) agar senantiasa melakukan pemeriksaan kolesterol.

2. Kepada para pengambil kebijakan agar alat dan bahan untuk pemeriksaan kolesterol sedapat mungkin disiapkan untuk pemeriksaan secara gratis atau dalam tanggungan asuransi kesehatan.

\section{DAFTAR PUSTAKA}

Beavers,.D.G, 2008. Tekanan Darah.Pt, Dian Rakyat, Jakarta

Fikri, Fairuz. 2009. Bahaya Kolesterol: Memahami, Mendeteksi, dan Mengontrol kolesterol. Katahati. Yogyakarta.

Junaidi I, 2010. Hipertensi. Pengenalan, Pencegahan, dan Pengobatan,.Klompok Gramedia, Egc.jakarta.

McPhee, Stephen J., William F. Ganong. 2015. Patologi Penyakit: Pengantar Menuju Kedokteraan Klinis edisi 5. Penerbit Buku Kedokteran EGC. Jakarta.

Soenarwo, Briliantono M. 2013. Jangan Takut Sehat. Halimun Media Citra. Jakarta.

Robert E., Kowalski, 2010. Terapi hipertensi: Program 8 Minggu Menurunkan Tekanan Darah Tinggi Dan Mengurangi Resiko Serangan Jantung Dan Stroke Secara Alami. Bandung : Qanita. 
Tabel 1 Distribusi Responden berdasarkan Jenis Kelamin

\begin{tabular}{lcc}
\hline Jenis Kelamin & N & \% \\
\hline Laki-Laki & 11 & 22 \\
\hline Perempuan & 39 & 78 \\
\hline Total & 50 & 100 \\
\hline
\end{tabular}

Sumber : Data Primer 2020

Tabel 2 Distribusi responden berdasarkan kadar kolesterol

\begin{tabular}{ccc}
\hline Kadar Kolesterol & n & \% \\
\hline Normal $(<200 \mathrm{mg} / \mathrm{dl})$ & 19 & 38 \\
\hline Tinggi $(\geq 200 \mathrm{mg} / \mathrm{dl})$ & 31 & 62 \\
\hline Total & 50 & 100
\end{tabular}

Sumber : Data primer 2020

Tabel 3 Distribusi responden berdasarkan tekanan darah kategori hipertensi

\begin{tabular}{|lll} 
Tekanan Darah & n & \% \\
\hline Normal & 31 & 62 \\
\hline Tinggi & 19 & 38
\end{tabular}

Sumber : Data Primer 2020

Tabel 4 Distribusi responden dengan kadar kolesterol berdasarkan jenis kelamin.

\begin{tabular}{lccl}
\hline Kadar Kolesterol Tinggi & n & & \% \\
\hline Laki-Laki & 5 & 16,1 & \\
\hline Perempuan & 26 & 83,9 & \\
\hline Total & 31 & 100 &
\end{tabular}

Sumber : Data primer 2020 